\title{
Factors associated with depressive symptoms in people living with HIV attending antiretroviral clinic at Fitche Zonal Hospital, Central Ethiopia: cross-sectional study conducted in 2012
}

\author{
This article was published in the following Dove Press journal: \\ Neuropsychiatric Disease and Treatment \\ 8 August 2017 \\ Number of times this article has been viewed
}

\author{
Tebikew Yeneabat' \\ Asres Bedaso ${ }^{2}$ \\ Tadele Amare ${ }^{3}$ \\ 'Department of Midwifery, College \\ of Health Sciences, Debre Markos \\ University, Debre Markos, Ethiopia; \\ ${ }^{2}$ School of Nursing and Midwifery, \\ College of Medicine and Health \\ Sciences, Hawassa University, \\ Hawassa, Ethiopia; ${ }^{3}$ Department of \\ Psychiatry, College of Medicine and \\ Health Sciences, University of Gondar, \\ Gondar, Ethiopia
}

\begin{abstract}
Background: Depression is one of the most common psychiatric disorders with the prevalence rate ranging from $5 \%$ to $10 \%$ in the general population and about $60 \%$ in people living with human immunodeficiency virus (PLHIV). It has been reported to be more common among women living with HIV. In HIV patients, depression can have negative impacts on their quality of life. Objective: This study was aimed at identifying the prevalence of depressive symptoms and associated factors among PLHIV attending the antiretroviral therapy clinic at Fitche Zonal Hospital.
\end{abstract}

Methods: It was a cross-sectional study conducted among PLHIV in Fitche Zonal Hospital from February 15 to March 15, 2012. Center for Epidemiologic Studies Depression tool was used to collect data from 390 respondents. Both the bivariate and multivariable logistic regression analyses were carried out and variables with $P<0.25$ in the bivariate logistic regression analysis were entered into multivariable logistic regression analysis and statistical significance was declared at $P<0.05$.

Results: Of the total 390 respondents included in the analysis, the prevalence of depressive symptoms was $76.7 \%$, ranging from mild to moderate (33.6\%) to major (43.1\%), and the highest proportion was observed among individuals with food insecurity accounting for $287(79.3 \%)$. Food insecurity (adjusted odds ratio [AOR] =3.832 [1.575-9.322]), non-ownership of livestock $(\mathrm{AOR}=2.17$ [1.157-4.104]), and opportunistic infections (AOR =5.20 [1.342-20.156]) were significantly associated with depressive symptoms.

Conclusion and recommendations: Depressive symptoms were prevalent in PLHIV. Social disparities were important factors of depressive symptoms. Integration of mental health care services with HIV/acquired immune deficiency syndrome-related health care services at all health care levels was necessary. It was recommended that government and non-government organizations should provide assistance to the PLHIV to encourage their involvement in income-generating activities.

Keywords: depression, PLHIV, Fitche, CES-D

\section{Background}

Evidence from the World Health Organization (WHO) and the National Institute of Mental Health (NIMH) revealed that mental health problem, particularly depression, has a significant link to human immunodeficiency virus/acquired immune deficiency syndrome (HIV/AIDS). Being infected with HIV is associated with increased occurrence of depression. ${ }^{1,2}$ Depression in general population caused by mental and
Correspondence: Tebikew Yeneabat Department of Midwifery, College of Health Sciences, Debre Markos University, Debre Markos, PO Box 269 Ethiopia

Tel +25 I 9| 2682742

Email wait4myfather@gmail.com 
substance use disorders is mentioned as the third leading cause of disease burden worldwide, and the problem is highly prevalent among women. It accounts for $4.3 \%$ of the global burden of disease from the total of $14 \%$ global burden of disability accounted by mental and substance use disorders. ${ }^{3,4}$ Depression is predicted to be the leading cause of disease burden by the year $2030 .^{5}$ It has been indicated to have a negative impact on the quality of life of people living with HIV (PLHIV) and increased AIDS disease progression. It is reported that AIDS-related deaths are more among those with chronic depressive symptoms. ${ }^{6}$ Although there is a significant link between depression and HIV/AIDS, depression is a stand alone illness that can and should be treated, even when a person is undergoing treatment for HIV/AIDS. Hence, it is one of the priority conditions covered by WHO's Mental Health Gap Action Program (mhGAP). ${ }^{7}$

Up to two-thirds of PLHIV have depression. ${ }^{8}$ International Association of Providers of AIDS Care (IAPAC) has estimated the prevalence of depression among PLHIV to be about $60 \%$ and is twice more common in women. The prevalence of depression in the general population ranges from 5\% to $10 \% .{ }^{9}$ According to the studies conducted in Nigeria, India, and China, the prevalence of depression in PLHIV attending antiretroviral therapy (ART) is $56.7 \%, 58.75 \%$, and $71.9 \%$, respectively. ${ }^{10-12}$ The study conducted in southern Ethiopia using the Hospital Anxiety and Depression Scale (HADS) has shown the prevalence of generalized psychological distress among HIV-infected to be $11 \% .^{13}$ Another study carried out in Ethiopia using Kessler-10 scale identified the prevalence of common mental disorders as $41 \%,{ }^{14}$ and it has also been indicated to be prevalent among tuberculosis (TB)/HIV comorbid patients. ${ }^{15}$

Different studies disclosed that depression is associated with different sociodemographic and health-related factors. It is persistently highly prevalent among the poor. ${ }^{16-18}$ Studies in Botswana and Uganda, for example, revealed that depression is associated with food insecurity and sex among PLHIV. ${ }^{17,19}$ The study carried out in Ethiopia has also revealed that it is associated with the place of residence, economic status, and occupational status. ${ }^{20}$

Depression among PLHIV has several adverse effects. It impacts not only the health status of PLHIV by causing disease progression and leading to death but also has a negative effect on drug adherence. ${ }^{1}$ Therefore, identifying the prevalence of depressive symptoms and the factors associated with it is crucial in resource-limited countries to address the intervention areas by integrating HIV/AIDS-related care services with other primary health cares and mental health care.

\section{Materials and methods Study setting and sample}

A cross-sectional study was conducted in Fitche Zonal Hospital. Data were collected from February 15 to March 15, 2012, through interview and document review (for CD4 level and opportunistic infection [OI]-related data). Trained nurses were involved in data collection. Two days intensive training was given to them on data collection tools, techniques of interview, and document review. Data collectors also participated in pre-test that was carried out 2 weeks before the actual data collection. The questionnaires were adapted and adopted from literature. ${ }^{21,22}$ This study was part of the data collected for the study of food insecurity among PLHIV attending ART clinic at Fitche Zonal Hospital. ${ }^{23}$

\section{Sample size and sampling technique}

The sample size was 401 calculated using single population proportion formula ${ }^{24}$ and the following parameters were considered.

$\mathrm{n}=$ total number of PLHIV coming to ART clinic in Fitch Zonal Hospital $(6,871)$

$Z=$ standard normal variable at $95 \%$ confidence level (1.96)

$p=$ the proportion of food insecurity among PLHIV in Ethiopia (50\%)

$d=$ the desired precision of the estimate

$$
\mathrm{n}=\text { sample size }=\frac{\left(Z \frac{\alpha}{2}\right)^{2} p(1-p)}{d^{2}}=384
$$

Then, the finite population correction formula was carried out since the calculated sample size was higher than $5 \%$ of the size of source population (6871) was calculated to be 364 . Finally, 10\% contingency for non-response rate was added and the final sample size was 401.

\section{Measurements and data quality}

Depression was assessed using the Center for Epidemiologic Studies Depression (CES-D) tool which consisted of 20 items with four Likert scale rating the frequency of depressive symptoms in the past week. Study subjects were asked for the frequency of depressive symptoms in the past week. The possible range of score is $0-60$, with higher scores indicating more symptoms, weighted by frequency of occurrence in the past week. The frequency of symptoms experienced in the past week by the respondents was scored as follows: 0 represents symptoms manifested none of the time or rarely 
( $<1$ day); 1 represents symptoms manifested in some or a little of the time (1-2 days); 2 represents symptoms manifested occasionally or in a moderate amount of the time (3-4 days); and 3 represents symptoms manifested for most or all of the time (5-7 days). Scoring was reversed for the item numbers $4,8,12$, and 16 , which are positively stated. The scores $<16$ were reported as the absence of depression symptoms, scores between 16 and 21 were reported as mild-to-moderate depression symptoms, and scores $>21$ were reported as major depression symptoms. The internal consistency (Cronbach's alpha) of the items was 0.85 in the general population and 0.90 in a psychiatric population. ${ }^{22}$ Pre-test was carried out with $5 \%$ of the sample size at Kuyu Hospital in Gerba Guracha Town and the reliability index (Cronbach's alpha) was 0.78 .

Occupational status was assessed as follows:

In this study, employed refers to respondents who were mainly working in government or non-government organizations. Unemployed in this study was reported as respondents who were not working in any government or non-government organization but engaged in any types of job.

Food insecurity was assessed using the household food insecurity assessment tool and coping strategy index (CSI) previously used in a study carried out in Jimma. ${ }^{25}$ The tool consists of six items scored as 1 representing "yes" and 0 representing "no". The possible range of the sum of the score is from 0 to 6 . The sum score of 0 was considered as absence of food insecurity, and $>0$ was considered as food insecurity. CSI was used to measure the level of food insecurity or hunger indirectly. It consists of 10 items measured in a Likert scale ranging from 1 representing "often true" to 3 representing "never true". The sum total score ranges from 10 to 30 . The higher the score the higher is the CSI, and it indicates increased severity of food insecurity.

The practice of agriculture and ownership of livestock were used to measure the individual's capacity for subsistence production. Hence respondents were asked about whether or not they have practiced agriculture and owned livestock.

Data on CD4 levels and OIs were collected through document review of the most recently recorded data.

\section{Data processing and analysis}

After data collection, data were checked for completeness (11 partially completed questionnaires were discarded), coded, entered, and then analyzed using Statistical Package for Social Science (SPSS) version 16.0 for windows. Both the bivariate and multivariable logistic regression analyses, using the enter method, were used to study factors associated with depression among PLHIV. Variables with $P<0.25$ in the bivariate logistic regression model were entered spontaneously in the multivariable logistic regression model to measure the effect of each category of each variable on the likelihood of depression while controlling the effects of the other variables (and their categories) included in the model. Variables with $P<0.05$ in multivariable logistic regression analysis were identified as significant factors associated with depression among PLHIV.

\section{Ethical consideration}

Ethical clearance was obtained from Jimma University College of Public Health and Medical Sciences. Written permission was secured from Fitche Zonal Hospital medical director and matron offices, which was provided to head nurses and staff nurses to get permission. Following that, study participants were briefed about the study and their written consents were secured before the interview was conducted. Study participants were informed that they had full right not to participate in the study and withdraw from interview whenever they like to do so. But, they had also been informed that their participation in the study was very important. In addition, the confidentiality of the information was assured, and privacy of the study participants was respected and kept as well.

\section{Results}

In this study, 390 completed questionnaires were included in the analysis. The mean $( \pm \mathrm{SD})$ age of the study participants was $35.78( \pm 9.26)$, and the majority $(67.2 \%)$ of the study participants were females out of which the majority (42.30\%) were not educated. About $93 \%$ of them were in the category of food insecurity, and $17.18 \%$ of the study respondents' CD4 count was $<200$. OIs were prevalent in $3.58 \%$ of respondents (Table 1).

The prevalence of depressive symptoms was $76.7 \%$ (95\% CI: 72.6-80.8). Almost one-third (33.6\%) of them had mild-to-moderate depressive symptoms and $43.1 \%$ of them had major depressive symptoms. The highest proportion (79.3\%) of depressive symptoms was among individuals in the category of food insecurity. The bivariate logistic regression showed that only gender was significantly associated with depression among sociodemographic characteristics. CSI, food insecurity, practice of agriculture, ownership of livestock, and the presence of symptoms of OIs were also associated with depression in the bivariate logistic regression analysis. However, only food insecurity, ownership of 
Table I Descriptive statistics of study population, Fitche Zonal Hospital, Central Ethiopia, 2012

\begin{tabular}{|c|c|c|}
\hline Variables & Frequency $(n)$ & Percentage \\
\hline \multicolumn{3}{|l|}{ Sex } \\
\hline Male & 128 & 32.82 \\
\hline Female & 262 & 67.18 \\
\hline \multicolumn{3}{|l|}{ Education } \\
\hline No education & 165 & 42.31 \\
\hline Primary school & 159 & 40.77 \\
\hline Secondary school & 45 & 11.54 \\
\hline College and above & 21 & 5.38 \\
\hline \multicolumn{3}{|l|}{ Marital status } \\
\hline Living with partner & 167 & 42.82 \\
\hline Have no partner & 223 & 57.18 \\
\hline \multicolumn{3}{|l|}{ Occupation } \\
\hline Employed & 56 & 14.36 \\
\hline Unemployed & 334 & 85.64 \\
\hline \multicolumn{3}{|l|}{ Place of residence } \\
\hline Urban & 291 & 74.62 \\
\hline Rural & 99 & 25.38 \\
\hline \multicolumn{3}{|l|}{ Access to food aids } \\
\hline Yes & 58 & 14.87 \\
\hline No & 332 & 85.13 \\
\hline \multicolumn{3}{|l|}{ Food security } \\
\hline Yes & 28 & 7.18 \\
\hline No & 362 & 92.82 \\
\hline \multicolumn{3}{|c|}{ Practice of agricultural activities } \\
\hline Yes & 99 & 25.38 \\
\hline No & 291 & 74.62 \\
\hline \multicolumn{3}{|l|}{ Ownership of livestock } \\
\hline Yes & 135 & 34.62 \\
\hline No & 255 & 65.38 \\
\hline \multicolumn{3}{|l|}{$\mathrm{CD}^{+}$level } \\
\hline$<200$ cells & 67 & 17.18 \\
\hline $200+$ cells & 323 & 82.82 \\
\hline \multicolumn{3}{|l|}{ Presence of Ols } \\
\hline Yes & 379 & 97.18 \\
\hline No & 11 & 2.82 \\
\hline
\end{tabular}

Abbreviation: Ols, opportunistic infections.

livestock, and OIs were significantly associated with depression in multivariable logistic regression (Table 2).

Women experienced twofold $(\mathrm{COR}=2.12$ [1.31-3.44], $P<0.005)$ depressive symptoms compared to men. However, statistical significance was marginal in multivariable logistic regression (AOR $=1.75$ [1.00-3.08], $P=0.05)$.

CSI was significantly associated with depressive symptoms $(\mathrm{COR}=1.02$ [1.00-1.03], $P<0.05)$. Similarly, respondents who were in the category of food insecurity were about five $(\mathrm{COR}=5.10$ [2.32-11.25], $P<0.001)$ times more likely to have symptoms of depression compared to food-secured individuals. Food insecurity was significantly associated with depressive symptoms in multivariable logistic regression (AOR =3.83 [1.58-9.32], $P<0.05)$.

Those who had not practiced agricultural activities were about twice $(\mathrm{COR}=2.01$ [1.21-3.34], $P<0.05)$ more likely to have depressive symptoms compared to those who had practiced agricultural activities; but it was not statistically significant in multivariable logistic regression $(\mathrm{AOR}=0.97$ [0.48-1.96], $P>0.05)$.

On the other hand, those who had no livestock were about three $(\mathrm{COR}=2.72$ [1.68-4.40], $P<0.001)$ times more likely to have depressive symptoms compared to those who had livestock. It was also statistically significant in multivariable logistic regression that those who had no livestock were about twice $(\mathrm{AOR}=2.17$ [1.16-4.10], $P<0.05)$ more likely to have depressive symptoms.

The presence of signs and symptoms of OIs was not associated with depressive symptoms in the bivariate logistic regression $(\mathrm{COR}=2.84$ [0.85-9.53], $P=0.09$ ). However, it was significant $(\mathrm{AOR}=5.20$ [1.34-20.16], $P<0.05)$ in multivariable logistic regression.

\section{Discussion}

The prevalence of depressive symptoms was $76.7 \%$, which is almost similar to the finding from China $(71.9 \%),{ }^{12}$ but higher compared to Nigeria (56.7\%), India (58.75\%), and the global estimation $(60 \%) .{ }^{9-11}$ This could be attributed to the social impacts of food insecurity as food insecurity was highly prevalent (92.8\%) in the study population and found to be significantly associated with depression. Similarly, depression score was significantly correlated with CSI of food insecurity ( $r=0.29, P<0.05)$. As CSI increases, the score of depressive symptoms also increases and a higher CSI indicates the higher food insecurity status.

In this study, gender was marginally significant and associated with depression. Women were about twice more likely to experience depressive symptoms compared to men. The studies in Uganda ${ }^{19,26}$ also revealed that depression is higher in women than in men. However, the previous study carried out in Adigrat, Ethiopia, ${ }^{20}$ reported that gender is not associated with depression. $\mathrm{NIMH}^{2}$ stated that the possible reason for the higher proportion of depression among women could be attributed to biological, life cycle, hormonal, and psychosocial factors.

Individuals with food insecurity were found to be four times more likely to experience depressive symptoms compared to those who had no food insecurity. This finding is consistent with studies conducted in Uganda ${ }^{19,26}$ that revealed depression is high among those who were in the category of food insecurity. Facing food insecurity is a double burden condition for PLHIV, putting them into adverse health outcomes including mental health problems, particularly depression. ${ }^{19}$ This study indicated that there was a positive 
Table 2 The bivariate and multivariable logistic regression of factors associated with depression among people living with HIV/AIDS, Fitche Zonal Hospital, Central Ethiopia, 2012

\begin{tabular}{|c|c|c|c|c|c|c|}
\hline \multirow[t]{3}{*}{ Variables } & \multicolumn{6}{|c|}{ Presence of depressive symptoms } \\
\hline & \multicolumn{6}{|c|}{ Frequency, mean } \\
\hline & Yes & No & COR $(95 \% \mathrm{Cl})$ & $P$-value & $\operatorname{AOR}^{a}(95 \% \mathrm{Cl})$ & $P$-value \\
\hline \multicolumn{7}{|l|}{ Sex } \\
\hline Male & 86 & 42 & I & & I & \\
\hline Female & 213 & 49 & $2.123(1.311-3.439)$ & 0.002 & $1.754(1.00-3.075)$ & 0.050 \\
\hline Age, years, mean $\pm S D$ & $35.78( \pm 9.27)$ & & $0.991(0.967-1.016)$ & 0.482 & - & \\
\hline \multicolumn{7}{|l|}{ Education } \\
\hline No education & 137 & 28 & $1.529(0.518-4.518)$ & 0.442 & $0.811(0.183-3.582)$ & 0.782 \\
\hline Primary school & 120 & 39 & $0.962(0.33 \mathrm{I}-2.795)$ & 0.943 & $0.538(0.13-2.215)$ & 0.391 \\
\hline Secondary school & 26 & 19 & $0.428(0.133-1.372)$ & 0.153 & $0.248(0.062-0.999)$ & 0.050 \\
\hline College and above & 16 & 5 & I & & I & \\
\hline \multicolumn{7}{|l|}{ Marital status } \\
\hline Living with partner & 124 & 43 & I & & - & \\
\hline Have no partner & 175 & 48 & $1.264(0.789-2.026)$ & 0.330 & & \\
\hline \multicolumn{7}{|l|}{ Occupation ${ }^{\mathrm{b}}$} \\
\hline Employed & 39 & 17 & I & & I & \\
\hline Unemployed & 260 & 74 & $1.532(0.819-2.862)$ & 0.182 & $1.05 \mathrm{I}(0.424-2.605)$ & 0.915 \\
\hline \multicolumn{7}{|l|}{ Place of residence } \\
\hline Urban & 223 & 68 & $0.992(0.579-1.703)$ & 0.978 & - & \\
\hline Rural & 76 & 23 & I & & I & \\
\hline Number of dependent children & $0.87( \pm 0.72)$ & & $0.795(0.576-1.097)$ & 0.163 & $0.854(0.587-1.242)$ & 0.409 \\
\hline CSI & $23.24( \pm 26.08)$ & & $1.018(1.004-1.033)$ & 0.015 & $1.010(0.997-1.023)$ & 0.126 \\
\hline \multicolumn{7}{|l|}{ Access to food aids } \\
\hline Yes & 48 & 10 & I & & I & \\
\hline No & 251 & 81 & $0.646(0.312-1.334)$ & 0.237 & $0.763(0.327-1.78 I)$ & 0.532 \\
\hline \multicolumn{7}{|l|}{ Food security } \\
\hline Yes & 12 & 16 & I & & I & \\
\hline No & 287 & 75 & $5.102(2.3 \mid 5-1.247)$ & 0.000 & 3.832 ( $1.575-9.322)$ & 0.003 \\
\hline \multicolumn{7}{|l|}{ Practice of Agriculture } \\
\hline Yes & 66 & 33 & I & & I & \\
\hline No & 233 & 58 & $2.009(1.209-3.336)$ & 0.007 & $0.968(0.478-1.962)$ & 0.929 \\
\hline \multicolumn{7}{|l|}{ Ownership of livestock } \\
\hline Yes & 87 & 48 & I & & $\mathrm{I}$ & \\
\hline No & 212 & 43 & $2.720(1.68 I-4.402)$ & 0.000 & $2.17(1.157-4.104)$ & 0.016 \\
\hline \multicolumn{7}{|l|}{$\mathrm{CD4}^{+}$level } \\
\hline$<200$ cells & 52 & 15 & $\mathrm{I} .067(0.568-2.00 \mathrm{I})$ & $0.84 I$ & - & \\
\hline $200+$ cells & 247 & 76 & I & & & \\
\hline \multicolumn{7}{|l|}{ Presence of Ols } \\
\hline Yes & 293 & 86 & $2.839(0.846-9.530)$ & 0.091 & $5.20(1.342-20.156)$ & 0.017 \\
\hline No & 6 & 5 & I & & I & \\
\hline
\end{tabular}

Notes: a Model fitness checked with Hosmer and Lemeshow test $\left(\chi^{2}=6.259, \mathrm{df}=8, P=0.618\right)$. ${ }^{\mathrm{b} E m p l o y e d ~ r e p r e s e n t s ~ t h o s e ~ w h o ~ w o r k ~ i n ~ e i t h e r ~ g o v e r n m e n t ~ o r ~ n o n-g o v e r n m e n t ~}$ organization with monthly salary and Unemployed represents those who were engaged in other work not based on monthly salary.

Abbreviations: AOR, adjusted odds ratio; COR, crude odds ratio; CSI, coping strategy index; HIV/AIDS, human immunodeficiency virus/acquired immune deficiency syndrome; Ols, opportunistic infections.

correlation $(r=0.29, P<0.05)$ between a score of depressive symptoms and CSI.

WHO proved that mental health problems and poverty interact in a negative cycle: mental ill-health impedes people's ability to perform their daily activities and to engage productively in their economies, and poverty, in turn, increases the risk of developing mental disorders and reduces people's ability to gain access to health services. ${ }^{4}$ Slightly less than two-third (65.4\%) of the respondents had no livestock.
Even though it is not a sole indicator, ownership of livestock can pinpoint the level of poverty. In this study, nonownership of livestock was associated with more likelihood of depression. The risk was about twofold more in those who had no livestock. Studies have also corroborated depression is common among poor social-class individuals. ${ }^{16,18}$

This finding indicated that depression and OIs are common comorbidities of PLHIV. They have also shown synergistic effects on the disease progression and AIDS-related 
mortalities. Depression has an effect on immunosuppression, and immunosuppression inversely predisposes depression. ${ }^{27}$ Those who had developed OIs were about five times more likely to have depressive symptoms. This could be attributed to the feeling of the fear that their health condition is deteriorating as they manifest the multiple signs and symptoms of illness from HIV/AIDS. It agrees with the study ${ }^{28}$ that revealed depression among PLHIV is associated with progression of the disease. Unlike the previous studies, ${ }^{11,20}$ occupational status was not associated with depression.

This study will have social desirability and recall biases. The validity of CES-D in Ethiopia was not checked. This study did not include PLHIV who did not register and attend ART clinic and hence cannot be generalized to the general population.

\section{Conclusion}

Depression was prevalent in the study population. Women were found more likely to have depressive symptoms. Food insecurity and non-ownership of livestock were associated with depression and PLHIV who reported signs and symptoms of OIs were more likely to have depressive symptoms. This study concluded that social disparity, as explained by food insecurity and non-ownership of livestock, was a predictor of depressive symptoms among PLHIV and progression of the disease was positively related to depressive symptoms.

\section{Recommendations}

Based on the findings, integration of mental health care services into HIV/AIDS-related care services at all health care delivery levels would have importance in early detection and treatment of depressive symptoms among PLHIV. Implementing the poverty reduction strategy designed by United Nations Development Program (UNDP) ${ }^{29}$ is essential in the study area. HIV/AIDS-related health care services at all levels need to include an assessment of mental disorders and their appropriate management. It is important to counsel PLHIV on the disease process while providing treatment and care for OIs. Government and non-government organizations should assist PLHIV to involve in income-generating activities.

Further studies should be carried out in large scale addressing diverse factors including stigma and discrimination.

\section{Acknowledgments}

We would like to acknowledge the study participants, Fitche Hospital, and Jimma University. We are indebted to thank Dr Haile Kassahun (PhD, Assistant Professor of TEFL at
Debre Markos University) who substantially revised, edited, and corrected the grammar of the final manuscript.

\section{Author contributions}

The authors' responsibilities were as follows: TY conceived, designed and supervised the study. AB and TA assisted during the conception and design. TY, AB and TA carried out data analysis, interpreted the data, wrote and critically revised the manuscript. All authors read and approved the final manuscript.

\section{Disclosure}

The authors report no conflicts of interest in this work.

\section{References}

1. WHO. HIV/AIDS and Mental Health: Report by the Secretariat. Geneva: World Health Organization; 2008.

2. National Institute of Mental Health [webpage on the Internet]. NIMH Depression; 2011. Available from: http://www.nimh.nih.gov/health/ publications/depression/index.shtml\#pub4. Accessed December 24, 2014.

3. WHO. Mental Health Action Plan 2013-2020. Geneva: World Health Organization; 2013.

4. WHO. mhGAP: Mental Health Gap Action Programme: Scaling Up Care for Mental, Neurological and Substance Use Disorders. Geneva: World Health Organization; 2008.

5. WHO. Global Burden of Mental Disorders and the Need for a Comprehensive, Coordinated Response from Health and Social Sectors at the Country Level: Report by the Secretariat. Geneva: World Health Organization; 2011.

6. Cook JA, Grey D, Burke J, Cohen MH, et al. Depressive symptoms and AIDS-related mortality among a multisite cohort of HIV-Positive women. Am J Public Health. 2004;94(7):1133-1140.

7. WHO [webpage on the Internet]. Depression. Available from: http:// www.who.int/mediacentre/factsheets/fs369/en/. Accessed December 22, 2014.

8. WHO [webpage on the Internet]. Mental health, poverty and development. Available from: http://www.who.int/mental_health/policy/ development/en/. Accessed December 25, 2014.

9. IAPAC [webpage on the Internet]. Depression and HIV. aidsinfonet. org. The AIDS InfoNet. Available from: http://www.aidsinfonet.org/ fact_sheets/view/558. Accessed December 23, 2014.

10. Shittu RO, Issa BA, Olanrewaju GT, et al. Social determinants of depression: social cohesion, negative life events, and depression among people living with HIV/AIDS in Nigeria, West Africa. Int J MCH AIDS. 2014;2(2):174-181.

11. Bhatia MS, Munjal S. Prevalence of depression in people living with HIV/AIDS undergoing ART and factors associated with it. JClin Diagn Res. 2014;8(10):WC01-WC04.

12. Su X, Lau JT, Mak WW, et al. Prevalence and associated factors of depression among people living with HIV in two cities in China. $J$ Affect Disord. 2013;149(1-3):108-115.

13. Tesfaye SH, Bune GT. Generalized psychological distress among HIVinfected patients enrolled in antiretroviral treatment in Dilla University Hospital, Gedeo zone, Ethiopia. Glob Health Action. 2014;7:23882.

14. Deribew A, Deribe K, Reda AA, Tesfaye M, Hailmichael Y, Maja T. Do common mental disorders decline over time in TB/HIV co-infected and HIV patients without TB who are on antiretroviral treatment? BMC Psychiatry. 2013;13:174.

15. Deribew A, Tesfave M, Hailmichael $Y$, et al. Common mental disorders in TB/HIV co-infected patients in Ethiopia. BMC Infect Dis. 2010;10:201. 
16. Murali V, Oyebode F. Poverty, social inequality and mental health. $A d$ Psychiatr Treat. 2004;10:216-224.

17. Gupta R, Dandu M, Packel L, et al. Depression and HIV in Botswana: A Population-Based Study on Gender-Specific Socioeconomic and Behavioral Correlates. PLoS ONE. 2015;5(12):e14252.

18. Kinyanda E, Woodburn P, Tugumisirize J, et al. Poverty, life events and the risk for depression in Uganda. Soc Psychiatry Psychiatr Epidemio. 2011;46(1):35-44.

19. Tsai AC, Bangsberg DR, Frongilla EA, et al. Food Insecurity, Depression and the Modifying Role of Social Support among People Living with HIV/AIDS in Rural Uganda. Soc Sci Med. 2012;74(12): 2012-2019.

20. Berhe H, Bayray A. Prevalence of depression and associated factors among people living with HIV/AIDS in Tigray, North Ethiopia: a cross sectional hospital based study. IJPSR. 2013:4(2):665-775.

21. Central Statistical Agency [Ethiopia] and ICF International. Ethiopia Demographic and Health Survey 2011. Addis Ababa, Ethiopia and Calverton, MD: Central Statistical Agency and ICF International; 2012.

22. Center for Epidemiologic Studies Depression Scale (CES-D), NIMH. Available from: www.chcr.brown.edu/pcoc/cesdscale.pdf. Accessed: December 23, 2014.
23. Tolasa B, Belachew T. Food insecurity and associated factors among people living with HIV/AIDS attending ART clinic in Fitche Zonal Hospital, Fitche town, Oromia region, North Ethiopia. In press 2012.

24. Daniel WW. Biostatistics: A Foundation for Analysis in the Health Sciences. John Wiley and Sons, 1999.

25. Belachew T, Hadley C, Lindstorm D, Gebremariam A, Lachat C, Kolsteren P. Food insecurity, school absenteeism and educational attainment of adolescents in Jimma Zone Southwest Ethiopia: a longitudinal study. Nutrn J. 2011;10:29.

26. Kinyanda E, Hoskins S, Nakku J, Nawaz S, Patel V. Prevalence and risk factors of major depressive disorder in HIV/AIDS as seen in semiurban Entebbe district, Uganda. BMC Psychiatry. 2011;11:205.

27. Depression and HIV - HIV/AIDS [webpage on the Internet]. Available from: http://www.hiv.va.gov/provider/manual-primary-care/depression. asp. Accessed December 26, 2014.

28. Cook J, Grey D, Burke J, et al. Depressive Symptoms and AIDS-Related Mortality Among a Multisite Cohort of HIV-Positive Women. Am J Public Health. 2004;94(7):1133-1140.

29. UNDP, New York. HIV/AIDS and poverty reduction strategies: Policy Note. (2002).
Neuropsychiatric Disease and Treatment

\section{Publish your work in this journal}

Neuropsychiatric Disease and Treatment is an international, peerreviewed journal of clinical therapeutics and pharmacology focusing on concise rapid reporting of clinical or pre-clinical studies on a range of neuropsychiatric and neurological disorders. This journal is indexed on PubMed Central, the 'PsycINFO' database and CAS,

\section{Dovepress}

and is the official journal of The International Neuropsychiatric Association (INA). The manuscript management system is completely online and includes a very quick and fair peer-review system, which is all easy to use. Visit http://www.dovepress.com/testimonials.php to read real quotes from published authors. 